\title{
Markers in Morphine- and Cocaine-Addicted Animals
}

\author{
Zhenzhen Hu${ }^{1}$, Kwang-Soon Park', Jin-Yi Han², Choon-Gon Jang ${ }^{3}$, Seikwan Oh${ }^{4}$, Hyoung-Chun Kim ${ }^{5}$, Chae Ha \\ Yang $^{6}$, Eun-Jeong $\mathrm{Kim}^{7}$ and Ki-Wan $\mathrm{Oh}^{1, *}$ \\ ${ }^{1}$ College of Pharmacy, Chungbuk National University, Cheongju 361-763, \\ ${ }^{2}$ Research Institute of Veterinary Medicine, Chungbuk National University, Cheongju 361-763, \\ ${ }^{3}$ School of Pharmacy, Sungkyunkwan University, Suwon 440-746, \\ ${ }^{4}$ College of Medicine, Ewha Womans University, Seoul 158-701, \\ ${ }^{5}$ College of Pharmacy, Kangwon National University, Chuncheon 200-701, \\ ${ }^{6}$ College of Oriental Medicine, Daegu Haany University, Daegu 706-060, \\ ${ }^{7}$ Korea Food and Drug Administration, Seoul 122-704, Republic of Korea
}

\begin{abstract}
These experiments were designed to use typical makers from behaviors and molecular basis in addicted animals of morphine and cocaine. Morphine has been widely abused with a high physical dependence liability. Morphine withdrawal activates the intracellular cAMP signaling pathway and further leads to changes in the expression of the cAMP response element binding protein (CREB), which may be important to the development and expression of morphine dependence. From these experiments, repeated morphine $(10 \mathrm{mg} / \mathrm{kg}$, twice per day for 7 days) developed physical dependence. Withdrawal signs were precipitated by naloxone and also increased the expression of the CREB. In addition, repeated exposure of cocaine $(15 \mathrm{mg} / \mathrm{kg})$ to mice develops locomotor sensitization and produced lasting behavioral sensitivity. Cocaine- and amphetamine-regulated transcript peptide (CART) peptide was up-regulated by repeated administration of cocaine in the striatum. Therefore, repeated morphine induced the development of physical dependence and increased $p C R E B$. In addition, repeated cocaine induced locomotor sensitization and over-expressed CART peptide. In conclusion, the development of physical dependence and pCREB for morphine, and locomotor sensitization and CART peptide over-expression for cocaine would be useful markers to predict the abuse potential of opioid analgesics and pychostimulant drugs in animals, respectively.
\end{abstract}

Key Words: Marker, Morphine, Cocaine, Addiction, pCREB, CART

\section{INTRODUCTION}

Addiction is a chronic relapsing disease, often accompanied by several neurological impairments such as deficits in cognition, motivation, insight and attention, behavioral disinhibition, emotional instability, depression, anhedonia, impulsiveness, aggressiveness and movement disorders (Morley et al., 1980; Majewska, 1996; Leshner, 1997; Kalivas, 2007). Opiates and psychostimulants produce addictions after repeated administrations in animals and human (Heyne and Wolffgramm, 1998; Sevarino et al., 2000).

Opiates such as heroin and morphine remain widely abused drugs with a high physical dependence liability (Pouletty, 2002). Opiates, acting on opioid receptors via Gi/Go classes of the $\mathrm{G}$ proteins, inhibit cyclic AMP (cAMP) formation (Col- lier and Francis, 1975). These results in inhibition of neuronal excitability and synaptic transmission are mediated via cAMP and represent a classic cellular mechanism of opioid action. With continuing opioid exposure, activity of cAMP signaling gradually is recovered and is increased (up-regulation) above control level. Thus, prolonged exposure to opioids leads to tolerance of cAMP transmission at the single cell level. Abrupt removal of opioids after chronic exposure to these drugs induces subsequent adaptation that, at the cellular level, is manifested by an increase in cAMP levels and was suggested to represent a cellular model of tolerance and dependence (Nestler et al., 1993). Essentially similar regulation of the cAMP pathways was also demonstrated in vivo in certain brain structures. Opiates given acutely slightly inhibited the adenylyl cyclase, while this inhibition was gradually reversed during opioid tolerance

\section{www.biomolther.org}

Open Access DOI: 10.4062/biomolther.2011.19.1.045

pISSN: 1976-9148 elSSN: 2005-4483

Copyright $\odot 2011$ The Korean Society of Applied Pharmacology
Received Sep 13, 2010 Revised Nov 2, 2010 Accepted Nov 4, 2010

*Corresponding Author
E-mail: kiwan@cbnu.ac.kr
Tel: +82-43-261-2827, Fax: +82-43-261-2827 
and greatly increased during withdrawal in the locus coeruleus (LC) and other brain regions (Terwilliger et al., 1991; Mamiya et al., 2001). So, opioid withdrawal activates the intracellular cAMP signaling pathway. The increase in cAMP levels results in the activation of cAMP-dependent protein kinase (PKA) alterations in the phosphorylation of proteins relevant to opioid signaling and enhancement of transmitter release. The opiateinduced changes further lead to changes in the expression of the $\mathrm{Ca}^{+} / \mathrm{cAMP}$ response element binding protein (CREB), which may be important to the development and expression of opioid dependence (Nestler et al., 1993; Widnell et al., 1994; Maldonado et al., 1996). Furthermore, abundant evidences show the CREB activity in the nucleus accuments mediates the effects of the high physical dependence by morphine (Maldonado et al., 1996; Widnell et al., 1996).

Cocaine is widely recognized as one of the most addictive and dangerous illicit drugs used. Repeated exposure to psychostimulants such as cocaine and amphetamine can produce lasting behavioral sensitivity to these drugs in both humans and animals (Robinson and Becker, 1986). Consistently, in both humans and animals after repeated exposure to cocaine and amphetamine, Cocaine- and amphetamine-regulated transcript peptide (CART) over-expression is found in nucleus accumbens (NAcc) (Douglass et al., 1995; Hurd and Fagergren, 2000). CART is widely but specifically distributed throughout the mammalian nervous system and participates in many physiological functions including food intake, drug addiction, stress and sensory process (Thim et al., 1998; Seress et al., 2004). Activation of intracellular signaling pathways by acting at putative receptors has been proposed to contribute to the biological effects of CART (Bannon et al., 2001; Larsen and Hunter, 2006). Striatal CART mRNA was increased four or five fold following acute cocaine or amphetamine administration. In situ hybridization shows that CART mRNA expression within the neostriatum is specific to NAcc, with low levels present in the caudate-putamen (Hunter et al., 2005). Subsequent research has shown that CART is localized to large densecore vesicles that form symmetric synapses with dendrites within the monkey NAcc (Philpot and Smith, 2006). In addition, approximately $40 \%$ of CART-expressing neurons in the NAcc shell also express dopamine D2 or D3 receptors (Yang et al., 2005). The up-regulation of CART peptide by psychostimulants administration and the localization of CART within the NAcc points to a potential role of CART in psychostimulant effects.

The National Institute on Drug Abuse was founded in 1974, and since that time there have been significant advances in understanding the processes by which drugs of abuse cause addiction. Animal models that replicate key features of addiction are available, and these models have made it possible to characterize the brain regions that are important for addiction and other drug effects, such as physical dependence. A large number of drug-induced changes at the molecular and cellular levels have been identified in these brain areas and rapid progress is being made in relating individual changes to specific behavioral abnormalities in animal models of addiction. The current challenges are to translate this increasingly impressive knowledge of the basic neurobiology of addiction to human addicts, and to identify the specific genes that make some individuals either particularly vulnerable or resistant to addiction (Qureshi et al., 2000).

These experiments were designed to use typical makers from behaviors and molecular basis in addicted animals of morphine and cocaine. These markers also would be useful to predict the abuse potential of opioid analgesics and pychostimulant drugs in animals.

\section{MATERIALS AND METHODS}

\section{Animal and drugs}

C57BL/6 male mice weighting 25-30 g were used in all experiments. They were housed, 5-6 animals per cage with water and food available ad libitum under an artificial 12:12 (h) light/dark cycle (light at 07:00) and constant temperature (22 \pm $2^{\circ} \mathrm{C}$ ). The drugs used were morphine hydrochloride (Dae-Won Pharm. Co., Seoul, Korea) and naloxone (Sigma, St. Louis, MO, USA), cocaine (Sigma, St. Louis, MO, USA). All the drugs were dissolved in physiological saline.

\section{Measurement of physical dependence induced by mor- phine}

Morphine (5, 10 and $20 \mathrm{mg} / \mathrm{kg}$ ) was injected subcutaneously (s.c.) twice daily at $12 \mathrm{~h}$ intervals (8:00 and 20:00) for 7 days. Control mice were treated with saline under same conditions. After the final injections of morphine and saline, naloxone $(5 \mathrm{mg} / \mathrm{kg}$ ) was injected intraperitoneally (i.p.) for precipitation. Mice were placed in acrylcylinder (diameter: $10 \mathrm{~cm}$, height: $30 \mathrm{~cm}$ ) and quantified naloxone-precipitated withdrawal symptoms, respectively. Withdrawal signs such as jumping, rearing, chattering, wet dog shakes, ptosis, scratching, penis licking, tremors, diarrhea and weight loss were observed 30 min and evaluated.

\section{Measurement of sensitization induced by cocaine}

The locomotor activity of mice was measured using a tilting-type ambulometer (AMB-10, O'Hara, Tokyo, Japan). Each mouse was placed in the activity cage $(20 \mathrm{~cm}$ in diameter, $18 \mathrm{~cm}$ in height). Mice were administered after an adaptation period of $10 \mathrm{~min}$. Cocaine $(5,15$ and $30 \mathrm{mg} / \mathrm{kg}$ ) was administered subcutaneously (s.c.) once a day for 7 days according to our previous methods to induce locomotor sensitization (Kim et al., 1997). Control mice were treated with saline under same conditions. The locomotor activity was measured for $1 \mathrm{~h}$ after the cocaine administration. The mice were first allowed to perambulate for $10 \mathrm{~min}$ in the activity cages followed by a 1-h test period immediately after the cocaine administration. The development of sensitization across 7 days was evidenced by an increased locomotor activity response to cocaine as compared with that of at day 1 .

\section{Measurement of $p$ CREB and CART expression using west- ern blotting}

All mice were sacrificed by decapitation $22 \mathrm{~h}$ after the last administration. The striatum was extracted at the coronal level between ${ }^{+} 0.7 \mathrm{~mm}$ and $-1.6 \mathrm{~mm}$ from the bregma according to the stereotaxic atlas including nucleus accumbens (Franklin and G.Paxinos, 1997). The striatum was dissected in ice-cold physiological saline and homogenized in PRO-PREPTM Protein solution (iNtRON Biotechnology Inc, Korea). Supernatants were collected and stored frozen. The protein concentration of the supernatant was determined using Bradford method with bovine serum albumin as the standard. Equal amount of proteins $(20 \mu \mathrm{g})$ were separated on a SDS/16\%-polyacrylamide 

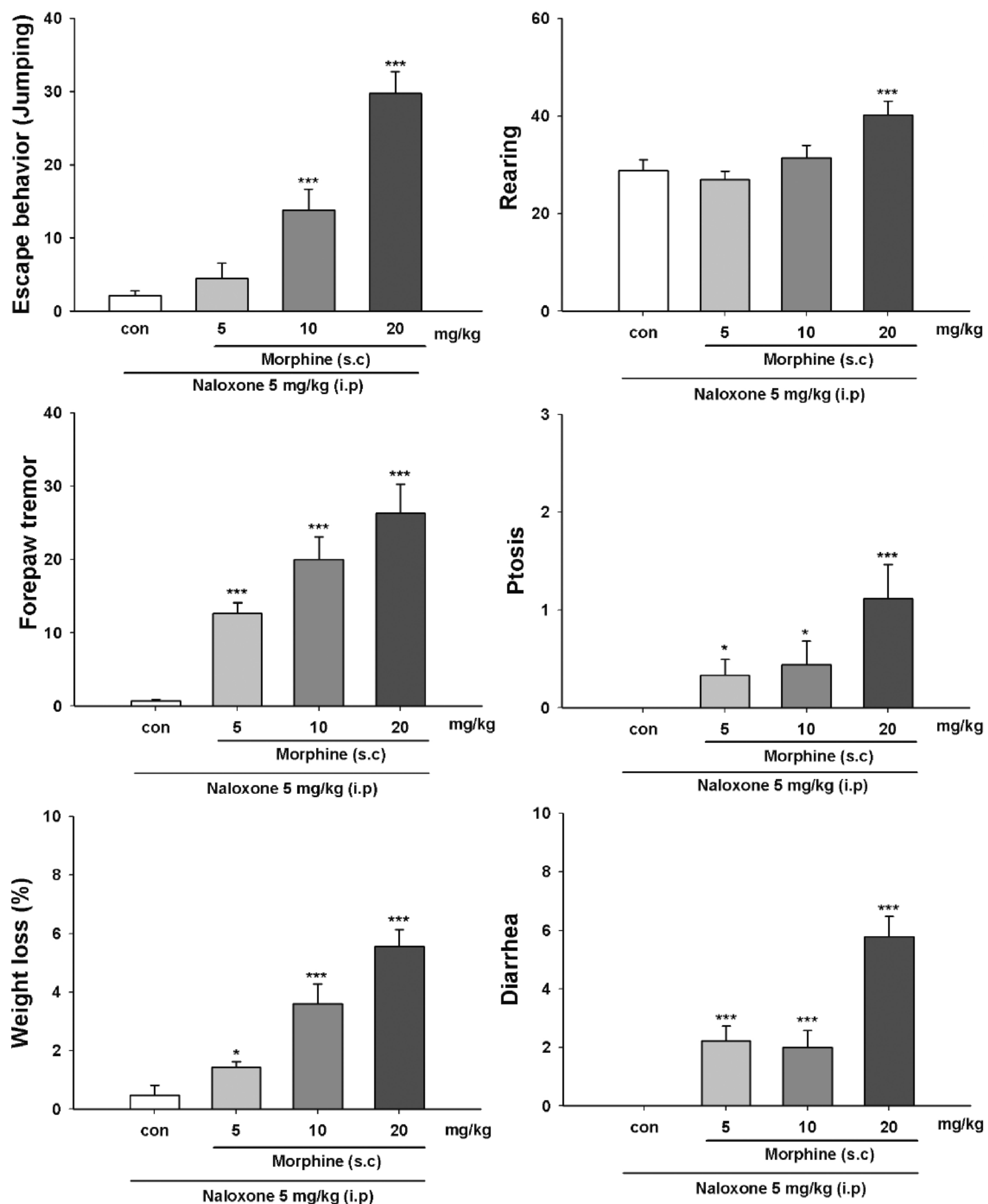

Fig. 1. Withdrawal signs induced by repeated administration of morphine. Morphine physical dependence was induced in mice by repeated injection (s.c.) of morphine $\mathrm{HCl}(5,10$ and $20 \mathrm{mg} / \mathrm{kg}$ ) twice daily during 7 days. C57BL/6 mice were precipitated by naloxone $\mathrm{HCl}(5 \mathrm{mg} / \mathrm{kg}$, s.c) 1 day after the last administration of morphine. Behavioral signs of withdrawal such as jumping, rearing, chattering, wet dog shakes, ptosis, scratching, penis licking, tremors, diarrhea and weight loss were evaluated using acrylcylinder. Data are expressed as the mean \pm SE, and significance was tested with a one-way ANOVA and Dunnett's test. The number of animals per group ranged from 9 to 13 . ${ }^{*} p<0.05$, ${ }^{* * *} p<0.005$ compared with saline group. 

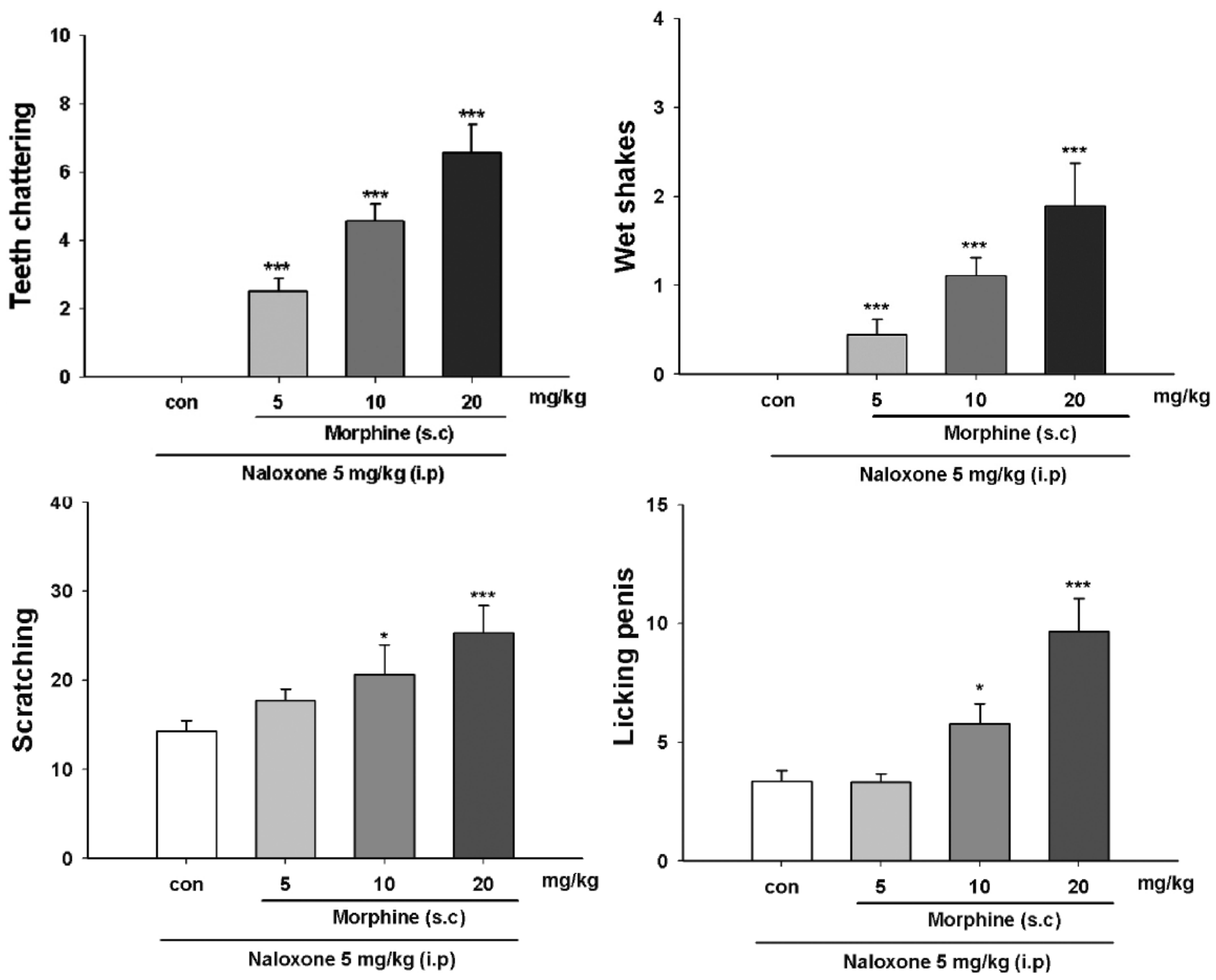

Fig. 1. Continued.

gel, and then transferred to a polyvinylidene difluoride (PVDF) membrane (Millipore Corporation, Bedford, MA, USA). The membrane was blocked for at least $2 \mathrm{~h}$ in $5 \%$ not-fat milk with TBS-T [10mM Tris ( $\mathrm{pH} 8.0$ ) containing $0.05 \%$ tween-20], followed by three washes for $10 \mathrm{~min}$ in TBS-T. Membranes were incubated overnight at $4^{\circ} \mathrm{C}$ with specific antibodies. The goat polyclonal antibody against CART (Santa Cruz Biotechnology Inc. Santa Cruz, CA) (1:200) and the rabbit polyclonal antibody against pCREB (Santa Cruz Biotechnology Inc. Santa Cruz, CA) (1:500) were used in study. The blot was then incubated with the corresponding conjugated anti-goat or antirabbit immunoglobulin G-horseradish peroxidase (Santa Cruz Biotechnology Inc. Santa Cruz, CA) (1:3,000). The immunoreactivity was revealed with incubation with the ECL-Plus chemiluminescent substrate (Roche, Mannheim, Germany) for 5 min. Membranes were apposed to film for several exposures of varying duration. Quantitative analysis was conducted by measuring the relative optical density (OD) of the immunoactive signal between CART or $p C R E B$ and $\beta$-actin.

\section{Statistical data analysis}

All data are presented as mean \pm SE. Statistical significance $(p<0.05)$ was determined by one-way analysis of variance (ANOVA) followed by Dunnett's test. $p<0.05$ relative to the control group was considered to be significant.

\section{RESULTS}

\section{Physical dependence induced by morphine}

Morphine (5, 10 and $20 \mathrm{mg} / \mathrm{kg}$ )-induced withdrawal signs precipitated by naloxone such as such as jumping, rearing, chattering, wet dog shakes, ptosis, scratching, penis licking, tremors, diarrhea and weight loss were significantly increased (Fig. 1).

\section{pCREB over-expression induced by morphine in striatum}

Repeated administration of morphine $(5,10$ and $20 \mathrm{mg} / \mathrm{kg}$ ) increased $p C R E B$ protein expression, in a dose-dependent manner, in striatum (Fig. 2). 


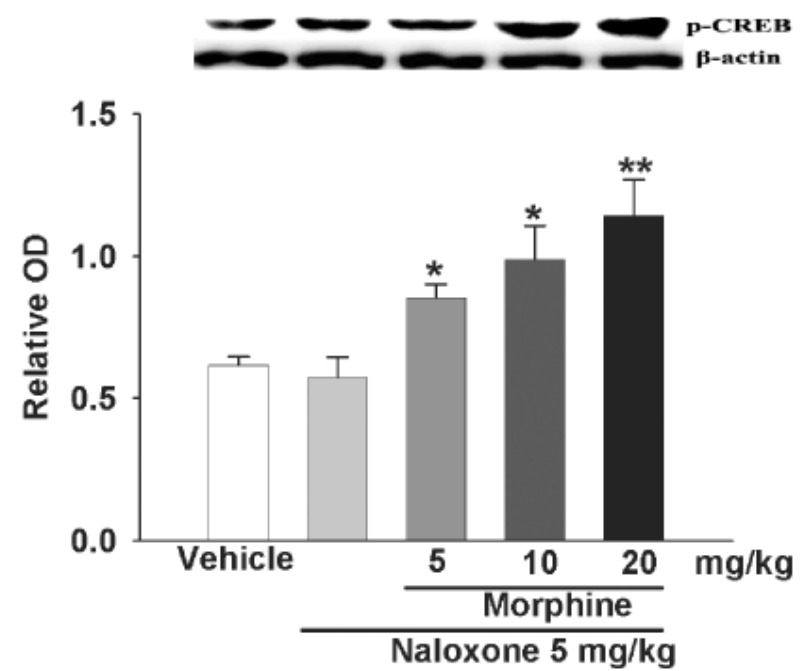

Fig. 2. $p C R E B$ over-expression induced by repeated administration of morphine. Morphine $(5,10$ and $20 \mathrm{mg} / \mathrm{kg}$ ) was subcutaneously administrated for 7 days. After the final morphine injection, C57BL/6 mice $(n=3)$ were sacrificed following naloxone $(5 \mathrm{mg} /$ $\mathrm{kg}$ ) administration. For each animal, data from western blotting ( 3 times per animal) was averaged prior to analysis. Quantitative analysis was conducted by measuring the relative OD of the immunoactive signal between $p$ CREB and $\beta$-actin. Data are expressed as the mean $\pm \mathrm{SE}$, and significance was tested with a one-way ANOVA and Dunnett's test. Significant differences from vehicle control $\left({ }^{*} p<0.01,{ }^{* *} p<0.001\right)$.

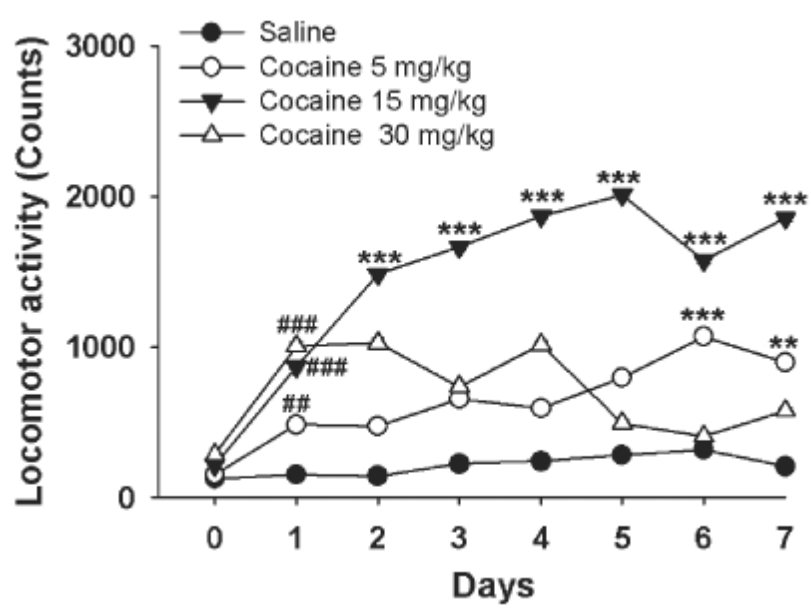

Fig. 3. Sensitization induced by repeated administration of cocaine. Cocaine $(5,15,30 \mathrm{mg} / \mathrm{kg})$ was administrated to C57BL/6 mice by repeated injection (s.c.) of cocaine daily for 7 days. Locomotor activity was measured by tilting-type ambulometer. Data are expressed as the mean $\pm \mathrm{SE}$, and significance was tested with a one-way ANOVA and Dunnett's test. ${ }^{* *} p<0.01,{ }^{* * *} p<0.001$ compared with that of cocaine treatment group day $1,{ }^{\#} p<0.01$, ${ }^{m}<0.001$ compared with that of saline treatment group.

\section{Locomotor sensitization induced by cocaine}

Cocaine (5, 15 and $30 \mathrm{mg} / \mathrm{kg})$-induced locomotor activity was significantly increased by the repeated administration of cocaine once a day for 7 days compared with that of cocaine
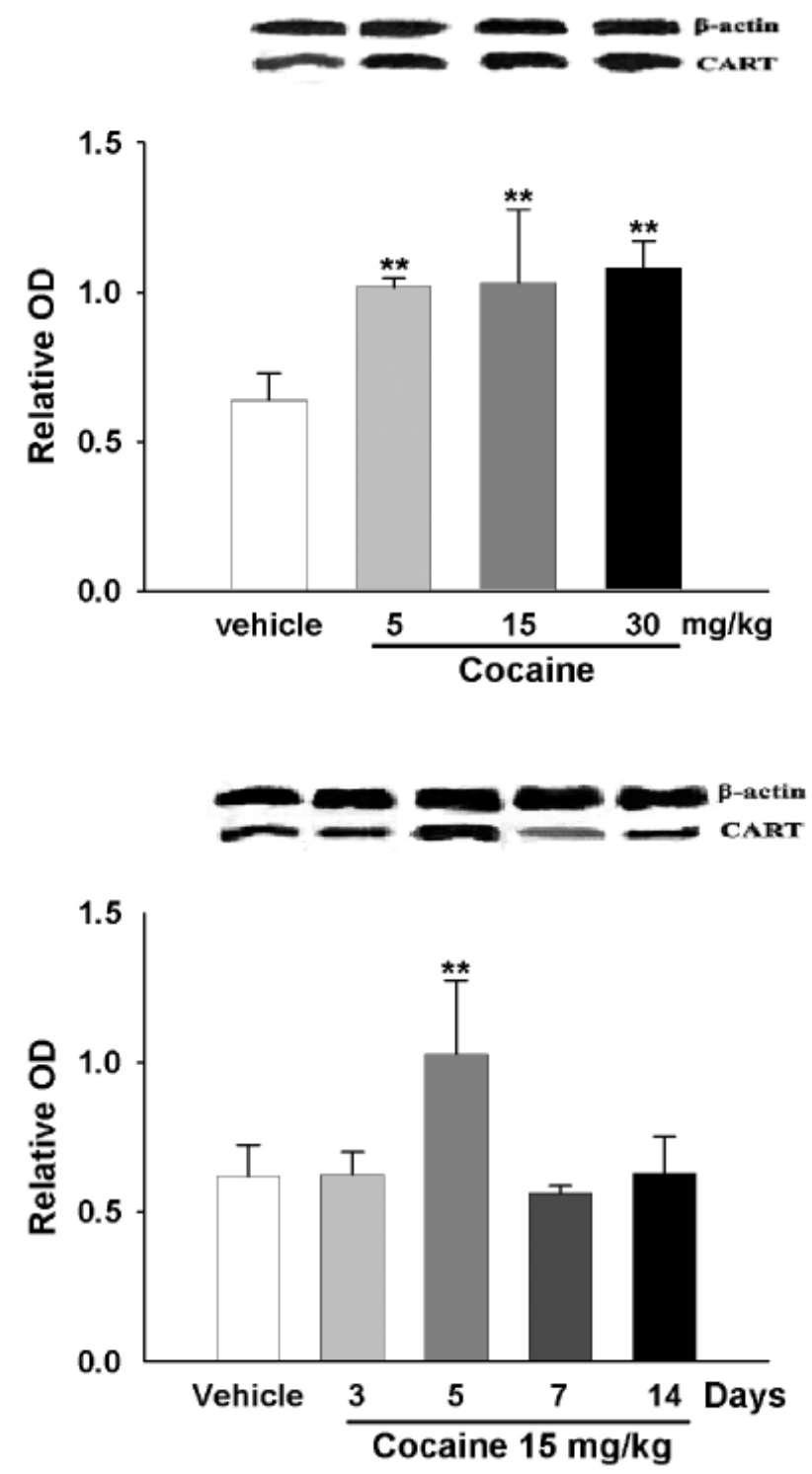

Fig. 4. CART peptide expression by cocaine. CART peptide was over-expression by cocaine in the mouse striatum. Upper panel: Cocaine $(5,15$ and $30 \mathrm{mg} / \mathrm{kg}$, s.c.) was administrated and animals were sacrificed following cocaine administration for 5 days. Lower panel: Mice were treated with cocaine $(15 \mathrm{mg} / \mathrm{kg}$, s.c.) for $3,5,7$ and 14 days. CART peptides expression was determined using western blotting. Quantitative analysis was conducted by measuring the relative OD of the immunoactive signal between CART and $\beta$-actin. Assays were run in triplicate and data represent the results obtained from three separate experiment. Data are expressed as the mean $\pm \mathrm{SE}$, and significance was tested with a one-way ANOVA and Dunnett's test. Significant differences from vehicle control $\left({ }^{* *} p<0.01\right)$.

treatment group day 1, suggesting the development of locomotor sensitization to cocaine (Fig. 3).

\section{CART peptide over-expression induced by cocaine}

The CART peptide over-expression was observed in striatum of cocaine treated mice. The up-regulation in CART peptide expression induced by repeated cocaine administration 
was on the dose of cocaine (5, 15 and $30 \mathrm{mg} / \mathrm{kg})$ (Fig. 4 A) and peaked at $5^{\text {th }}$ day on the dose of cocaine $(15 \mathrm{mg} / \mathrm{kg})$ (Fig. $\left.4 \mathrm{~B}\right)$.

\section{DISCUSSION}

Continuous use of opioids is limited by the risk of physical as well as psychological dependence, although morphine other opioids are widely used for its potent analgesic effects in the relief of moderate to severe pain. Moreover, it is very important to predict these deteriorative side effects such as physical dependence for the development of new opioid analgesics from the animal tests. Many kinds of withdrawal behaviors such as jumping, rearing, chattering, wet dog shakes, ptosis, scratching, penis licking, tremors, diarrhea and weight loss have been introduced to measure potential physical dependence liability in addicted animals of opioids. This animal model may provide a tool to predict dependence liability of opioid analgesics.

Although the mechanisms underlying the development of morphine dependence are not well understood, the best established mechanism of opioid-induced physical dependence at the molecular level involves up-regulation of CAMP pathway. This up-regulation of cAMP pathway involves increased levels of specific subtypes of adenylate cyclase, cAMP dependent PKA subunit. Up-regulation of CAMP pathway also takes place in neurons of nucleus accumbens and LC in the response to chronic administration of opioids (Lane-Ladd et al., 1997). On the other hand, synaptic plasticity is thought to be important in mediating certain behavioral effects of chronic opioid treatment. Activation of cAMP-activated transcription factor, CREB, is heavily implicated in various forms of synaptic plasticity. Also, because elevation in CAMP have long been considered central to the expression of opioid withdrawals, CREB is thought be important for withdrawals-dependent synaptic plasticity (Nestler et al., 1993). One well-studied transcriptional fact is CREB, which mediates many of the effects of the cAMP system on gene expression. Evidence for a role for CREB in drug action has been established for opioid dependence in the LC and nucleus accumbens. Chronic morphine administration increases CREB phosphorylation and expression in the brain region, which has led to the hypothesis that opiate regulation of CREB may mediate opioid-induced upregulation of the cAMP pathway in these neurons (Nestler et al., 1993; Lane-Ladd et al., 1997). Several lines of evidence indicate a role for CREB transcription factor. CREB mediated transcription is increased in the nucleus accumbens and elsewhere by chronic administration of opiates, and is increased even further during withdrawal (Hemby, 2004).

Cocaine is widely recognized as one of the most addictive and dangerous illicit drugs used. Typical to cocaine addiction is the emergence of both high craving for the drug and episodes of bingeing. Repeated exposure to psychostimulants such as cocaine and amphetamine can produce lasting behavioral sensitivity to these drugs in both humans and animals (Robinson and Becker, 1986). Neuropharmacological investigations demonstrate that repeated administration of cocaine leads to increase in ambulatory activity and rewarding properties, and dopaminergic systems play important roles in mediating the ambulatory and rewarding activities. It has been also demonstrated that one of the neural substrates mediating the ambulation-accelerating activity of cocaine-like psychomotor stimulants is an increase in extracellular dopamine levels in the nucleus accumbens (Kuczenski and Segal, 1989). Therefore, sensitization to cocaine-induced ambulation-accelerating activity is also attributable to the dopaminergic hyperfunction in the central nervous system (Taylor et al., 1979; Kalivas et al., 1988). From this experiment, we confirmed that cocaine increased ambulation/locomotor activities and induced sensitization after repeated administration. This animal model also may provide a tool to predict sensitization of psychostimulants.

It is a well-documented characteristic of psychomotor stimulants to produce a sensitization of locomotor activity with repeated doses. CART mRNA increases have been observed after administration of psychostimulants (Douglass et al., 1995; Fagergren and Hurd, 1999). Cocaine- and amphetamine-regulated transcript (CART) is a neuropeptide found throughout the brain, particularly in the NAcc and hypothalamus. CART peptide has been found in brain regions known to be associated with the actions of pychostimulant and other drugs that produce abuse and dependence. CART was initially discovered and named based on the up-regulation of its mRNA in the striatum after acute cocaine or amphetamine injection in rats (Koylu et al., 1998). Although this has been repeated by some (Hurd and Fagergren, 2000), it has been challenged by others (Marie-Claire et al., 2003). In responses to various repeated stimuli, levels of CART were elevated at the onset, peaked on the process and returned to normal on the end (Roh et al., 2009) with no corresponding difference from this experiment. However, it demonstrates that knockout mice lacking a functional CART gene show similar cocaine-induced locomotor sensitization and cocaine self-administration to their wild type siblings (Steiner et al., 2006). Therefore, the role for CART peptide involved in modulating the reward and reinforcing effects of psychostimulants, feeding behavior and central dopaminergic systems is clearer. Instead of different opinions on CART peptide over-expression and locomotor sensitization, one important confounding variable to consider when interpreting these studies is that cocaine can induce CART peptide. From our experiments, daily repeated cocaine administration maximally induced CART peptide over-expression at $5^{\text {th }}$ day. Locomotor sensitization was also maximally developed at the same day. Both CART peptide over-expression and sensitization were gradually reduced at $7^{\text {th }}$ and $14^{\text {th }}$ day-repeated administration of cocaine. Thus, these results suggest that the alteration in expression of CART peptides from up-regulation to down-regulation in striatum may generate feedback regulation as they modulated the development of locomotor sensitization in cocaine abuse. Consistently, a paper assume that CART would be a homeostatic regulator in striatum due to intra-NAcc CART 55-102 attenuation locomotor sensitization of cocaine (Jaworski et al., 2003). Taken together, CART peptide over-expression would be a maker to predict an abuse potential of psychostimulants.

In conclusion, the development of physical dependence and $p$ CREB for morphine, and locomotor sensitization and CART peptide over-expression for cocaine would be useful markers to predict the abuse potential of opioid analgesics and pychostimulant drugs in animals, respectively.

\section{ACKNOWLEDGMENTS}

This research was supported by Korea Food \& Drug Administration grants (10182KFDA535) and by the Korea Re- 
search Foundation Grant funded by the Korean Government (MOEHRD, Basic Research Promotion Fund) (KRF-2005005-J15002).

\section{REFERENCES}

Bannon, A. W., Seda, J., Carmouche, M., Francis, J. M., Jarosinski, M. A. and Douglass, J. (2001) Multiple behavioral effects of cocaine- and amphetamine-regulated transcript (CART) peptides in mice: CART 42-89 and CART 49-89 differ in potency and activity. J. Pharmacol. Exp. Ther. 299, 1021-1026.

Collier, H. O. and Francis, D. L. (1975) Morphine abstinence is associated with increased brain cyclic AMP. Nature 255, 159-162.

Douglass, J., McKinzie, A. A. and Couceyro, P. R. (1995) PCR differential display identifies a rat brain mRNA that is transcriptionally regulated by cocaine and amphetamine. J. Neurosci. 15, 24712481.

Fagergren, P. and Hurd, Y. L. (1999) Mesolimbic gender differences in peptide CART mRNA expression: effects of cocaine. Neuroreport. 10, 3449-3452.

Franklin, K. B. J., and Paxinos, G. (1997) The mouse brain in stereotaxic coordinates (A. Press, Ed.), San Diego.

Hemby, S. E. (2004) Morphine-induced alterations in gene expression of calbindin immunopositive neurons in nucleus accumbens shell and core. Neurosci. 126, 689-703.

Heyne, A. and Wolffgramm, J. (1998) The development of addiction to d-amphetamine in an animal model: same principles as for alcohol and opiate. Psychopharmacol (Berl). 140, 510-518.

Hunter, R. G., Vicentic, A., Rogge, G. and Kuhar, M. J. (2005) The effects of cocaine on CART expression in the rat nucleus accumbens: a possible role for corticosterone. Eur. J. Pharmacol. 517, 45-50.

Hurd, Y. L. and Fagergren, P. (2000) Human cocaine- and amphetamine-regulated transcript (CART) mRNA is highly expressed in limbic- and sensory-related brain regions. J. Comp. Neurol. 425, 583-598.

Jaworski, J. N., Kozel, M. A., Philpot, K. B. and Kuhar, M. J. (2003) Intra-accumbal injection of CART (cocaine-amphetamine regulated transcript) peptide reduces cocaine-induced locomotor activity. J. Pharmacol. Exp. Ther. 307, 1038-1044.

Kalivas, P. W. (2007) Neurobiology of cocaine addiction: implications for new pharmacotherapy. Am. J. Addict. 16, 71-78.

Kalivas, P. W., Duffy, P., DuMars, L. A. and Skinner, C. (1988) Behavioral and neurochemical effects of acute and daily cocaine administration in rats. J. Pharmacol. Exp. Ther. 245, 485-492.

Kim, H. S., Park, W. K., Jang, C. G., Oh, K. W., Kong, J. Y., Oh, S., Rheu, H. M., Cho, D. H. and Kang, S. Y. (1997) Blockade by naloxone of cocaine-induced hyperactivity, reverse tolerance and conditioned place preference in mice. Behav. Brain Res. 85, 37-46.

Koylu, E. O., Couceyro, P. R., Lambert, P. D. and Kuhar, M. J. (1998) Cocaine- and amphetamine-regulated transcript peptide immunohistochemical localization in the rat brain. J. Comp. Neurol. 391, 115-132.

Kuczenski, R. and Segal, D. (1989) Concomitant characterization of behavioral and striatal neurotransmitter response to amphetamine using in vivo microdialysis. J. Neurosci. 9, 2051-2065.

Lane-Ladd, S. B., Pineda, J., Boundy, V. A., Pfeuffer, T., Krupinski, J., Aghajanian, G. K., and Nestler, E. J. (1997) CREB (cAMP response element-binding protein) in the locus coeruleus: biochemical, physiological, and behavioral evidence for a role in opiate dependence. J. Neurosci. 17, 7890-7901.

Larsen, P. J. and Hunter, R. G. (2006) The role of CART in body weight homeostasis. Peptides 27, 1981-1986.

Leshner, A. I. (1997) Drug abuse and addiction treatment research. The next generation. Arch. Gen. Psychiatry 54, 691-694.

Majewska, M. D. (1996) Cocaine addiction as a neurological disorder: implications for treatment. NIDA. Res. Monogr. 163, 1-26.

Maldonado, R., Blendy, J. A., Tzavara, E., Gass, P., Roques, B. P., Hanoune, J. and Schutz, G. (1996) Reduction of morphine abstinence in mice with a mutation in the gene encoding CREB. Science 273, 657-659.

Mamiya, T., Noda, Y., Ren, X., Nagai, T., Takeshima, H., Ukai, M. and Nabeshima, T. (2001) Morphine tolerance and dependence in the nociceptin receptor knockout mice. J. Neural Transm. 108, 13491361.

Marie-Claire, C., Laurendeau, I., Canestrelli, C., Courtin, C., Vidaud, M., Roques, B. and Noble, F. (2003) Fos but not Cart (cocaine and amphetamine regulated transcript) is overexpressed by several drugs of abuse: a comparative study using real-time quantitative polymerase chain reaction in rat brain. Neurosci. Lett. 345, 77-80.

Morley, J. E., Yamada, T., Walsh, J. H., Lamers, C. B., Wong, H., Shulkes, A., Damassa, D. A., Gordon, J., Carlson, H. E. and Hershman, J. M. (1980) Morphine addiction and withdrawal alters brain peptide concentrations. Life Sci. 26, 2239-2244.

Nestler, E. J., Hope, B. T. and Widnell, K. L. (1993) Drug addiction: a model for the molecular basis of neural plasticity. Neuron 11, 9951006.

Philpot, K. and Smith, Y. (2006) CART peptide and the mesolimbic dopamine system. Peptides. 27, 1987-1992.

Pouletty, P. (2002) Drug addictions: towards socially accepted and medically treatable diseases. Nat. Rev. Drug Discov. 1, 731-736.

Qureshi, N. A., al-Ghamdy, Y. S. and al-Habeeb, T. A. (2000) Drug addiction: a general review of new concepts and future challenges. East Mediterr. Health J. 6, 723-733.

Robinson, T. E. and Becker, J. B. (1986) Enduring changes in brain and behavior produced by chronic amphetamine administration: a review and evaluation of animal models of amphetamine psychosis. Brain Res. 396, 157-198.

Roh, M. S., Cui, F. J., Ahn, Y. M. and Kang, U. G. (2009) Up-regulation of cocaine- and amphetamine-regulated transcript (CART) in the rat nucleus accumbens after repeated electroconvulsive shock. Neurosci. Res. 65, 210-213.

Seress, L., Abraham, H., Doczi, T., Lazar, G. and Kozicz, T. (2004) Cocaine- and amphetamine-regulated transcript peptide (CART) is a selective marker of rat granule cells and of human mossy cells in the hippocampal dentate gyrus. Neurosci. 125, 13-24.

Sevarino, K. A., Oliveto, A. and Kosten, T. R. (2000) Neurobiological adaptations to psychostimulants and opiates as a basis of treatment development. Ann. N. Y. Acad. Sci. 909, 51-87.

Steiner, R. C., Hsiung, H. M. and Picciotto, M. R. (2006) Cocaine selfadministration and locomotor sensitization are not altered in CART knockout mice. Behav. Brain Res. 171, 56-62.

Taylor, D. L., Ho, B. T. and Fagan, J. D. (1979) Increased dopamine receptor binding in rat brain by repeated cocaine injections. Commun. Psychopharmacol. 3, 137-142.

Terwilliger, R. Z., Beitner-Johnson, D., Sevarino, K. A., Crain, S. M. and Nestler, E. J. (1991) A general role for adaptations in G-proteins and the cyclic AMP system in mediating the chronic actions of morphine and cocaine on neuronal function. Brain Res. 548, 100-110.

Thim, L., Kristensen, P., Larsen, P. J. and Wulff, B. S. (1998) CART, a new anorectic peptide. Int. J. Biochem. Cell Biol. 30, 1281-1284.

Widnell, K. L., Russell, D. S. and Nestler, E. J. (1994) Regulation of expression of cAMP response element-binding protein in the locus coeruleus in vivo and in a locus coeruleus-like cell line in vitro. Proc. Natl. Acad. Sci. USA. 91, 10947-10951.

Widnell, K. L., Self, D. W., Lane, S. B., Russell, D. S., Vaidya, V. A., Miserendino, M. J., Rubin, C. S., Duman, R. S. and Nestler, E. J. (1996) Regulation of CREB expression: in vivo evidence for a functional role in morphine action in the nucleus accumbens. $J$. Pharmacol. Exp. Ther. 276, 306-315.

Yang, S. C., Shieh, K. R. and Li, H. Y. (2005) Cocaine- and amphetamine-regulated transcript in the nucleus accumbens participates in the regulation of feeding behavior in rats. Neurosci. 133, 841851. 